\title{
HUBUNGAN ANTARA KONVERGEN HAMPIR PASTI, KONVERGEN DALAM PELUANG, DAN KONVERGEN DALAM SEBARAN
}

\author{
VIRA AGUSTA, DODI DEVIANTO, HAZMIRA YOZZA \\ Program Studi Matematika, \\ Fakultas Matematika dan Ilmu Pengetahuan Alam, Universitas Andalas, \\ Kampus UNAND Limau Manis Padang, Indonesia, \\ agusta.vira@rocketmail.com,ddevianto@yahoo.com,hyozza@gmail.com
}

\begin{abstract}
Let $\left\{X_{n}\right\}$ be a sequence of random variable defined on a probability space $(\Omega, \mathfrak{F}, P)$. In this paper, we studied about the relationship between the convergence almost surely, convergence in probability, and convergence in distribution. If the sequence of random variable convergence almost surely to a random variable $X$ then $\left\{X_{n}\right\}$ convergence in probability to $X$. If the sequence of random variable $\left\{X_{n}\right\}$ convergence in probability to a random variable $X$ then $\left\{X_{n}\right\}$ convergence in distribution to $X$.
\end{abstract}

Kata Kunci: Convergence almost surely, convergence in probability, convergence in distribution.

\section{Pendahuluan}

Teori peluang sudah dikenal matematikawan sejak abad ke-17. Pada tahun 1709 Jaques (Jacob) Bernoulli menulis buku Ars Conjectandi, dimana salah satu isinya adalah tentang teori peluang. Teori peluang terkait dengan cara menentukan hubungan antara sejumlah kejadian khusus dengan jumlah kejadian sebarang. Kajian mengenai teori peluang adalah suatu kajian dalam matematika yang memungkinkan kita untuk menyediakan suatu dasar bagi pembentukan model yang terkait dengan fenomena-fenomena yang mengandung unsur ketidakpastian. Seseorang tidaklah mungkin untuk memahami statistika secara sempurna tanpa memahami apa arti peluang itu sendiri. Oleh karena itu, dapat dikatakan bahwa teori peluang adalah fondasi dari statistika.

Dalam teori peluang terdapat berbagai jenis kekonvergenan, diantaranya konvergen hampir pasti (convergence almost surely), konvergen dalam peluang, dan konvergen dalam sebaran. Menurut [1], barisan peubah acak $\left\{X_{n}\right\}$ dikatakan konvergen hampir pasti ke suatu peubah acak $X$ jika untuk setiap $\varepsilon>0$ berlaku

$$
P\left(\lim _{n \rightarrow \infty}\left|X_{n}-X\right|<\varepsilon\right)=1 .
$$

Dengan kata lain, konvergen hampir pasti adalah konvergen dengan peluang satu. Selanjutnya barisan peubah acak $\left\{X_{n}\right\}$ dikatakan konvergen dalam peluang ke suatu peubah acak $X$ jika untuk setiap $\varepsilon>0$ berlaku

$$
\lim _{n \rightarrow \infty} P\left(\left|X_{n}-X\right| \geq \varepsilon\right)=0
$$


sedangkan barisan peubah acak $\left\{X_{n}\right\}$ dikatakan konvergen dalam sebaran ke suatu peubah acak $X$ jika untuk $n \rightarrow \infty$ berlaku

$$
\lim _{n \rightarrow \infty} P\left(X_{n} \leq x\right)=P(X \leq x)
$$

untuk setiap $x$ dengan fungsi sebaran $F(x)=P(X \leq x)$ kontinu dari kanan [2].

Dalam berbagai referensi mengenai teori peluang disebutkan adanya hubungan antara kekonvergenan yang satu dengan kekonvergenan yang lain. Kajian mengenai hubungan antara beberapa jenis kekonvergenan dari peubah acak dalam teori peluang sangat menarik untuk dikaji karena keterpakaiannya dalam membantu pembuktian teorema-teorema tertentu. Dalam tulisan ini akan dikaji tentang hubungan antara konvergen hampir pasti, konvergen dalam peluang, dan konvergen dalam sebaran.

\section{Hubungan Antara Konvergen Hampir Pasti, Konvergen Dalam Peluang, dan Konvergen Dalam Sebaran}

Beikut diberikan definisi secara formal untukk kekonvergenan hampir pasti, kekonvergenan dalam peluang, serta kekonvergenan dalam sebaran.

Definisi 2.1. [1] Misalkan $\left\{X_{n}\right\}$ adalah barisan peubah acak yang didefinisikan pada suatu ruang peluang $(\Omega, \mathfrak{F}, P)$. Suatu barisan peubah acak $\left\{X_{n}\right\}$ dikatakan konvergen hampir pasti ke peubah acak $X$, jika untuk setiap $\varepsilon>0$ dan $n \rightarrow \infty$ berlaku

$$
P\left(\lim _{n \rightarrow \infty}\left|X_{n}-X\right|<\varepsilon\right)=1,
$$

ditulis $X_{n} \rightarrow^{h \cdot p} X$.

Definisi 2.2. [2] Misalkan $\left\{X_{n}\right\}$ adalah barisan peubah acak yang didefinisikan pada suatu ruang peluang $(\Omega, \mathfrak{F}, P)$. Suatu barisan peubah acak $\left\{X_{n}\right\}$ dikatakan konvergen dalam peluang ke peubah acak $X$, jika untuk setiap $\varepsilon>0$ dan $n \rightarrow \infty$ berlaku

$$
\lim _{n \rightarrow \infty} P\left(\left|X_{n}-X\right| \geq \varepsilon\right)=0
$$

ditulis $X_{n} \rightarrow^{p} X$.

Berdasarkan definisi diatas, akan dibentuk hubungan antar kekonvergenan dalam teorema-teorema berikut.

Definisi 2.3. [2] Misalkan $\left\{X_{n}\right\}$ adalah barisan peubah acak yang didefinisikan pada suatu ruang peluang $(\Omega, \mathfrak{F}, P)$. Suatu barisan peubah acak $\left\{X_{n}\right\}$ dikatakan konvergen dalam sebaran ke peubah acak $X$ untuk $n \rightarrow \infty$ berlaku

$$
\lim _{n \rightarrow \infty} P\left(X_{n} \leq x\right)=P(X \leq x)
$$

untuk semua titik $x$ dimana fungsi sebaran $F(x)=P(X \leq x)$ adalah suatu fungsi yang kontinu dari kanan, ditulis $X_{n} \rightarrow^{s} X$.

Teorema 2.4. [2] Jika barisan peubah acak $\left\{X_{n}\right\}$ konvergen dalam sebaran ke $c$ maka $\left\{X_{n}\right\}$ konvergen dalam peluang ke $c$. 
Bukti. Misalkan peubah acak $X$ menyebar secara degenerate ke nilai $c$. Dengan demikian fungsi sebaran dari $X$ dapat dituliskan sebagai

$$
F_{X}(x)=\left\{\begin{array}{l}
0, x<0 \\
1, x \geq 0
\end{array}\right.
$$

Misalkan pula $\left\{X_{n}\right\}$ adalah suatu barisan peubah acak. Perhatikan bahwa

$$
\begin{aligned}
P\left(\left|X_{n}-c\right|>\varepsilon\right) & =P\left[\left\{X_{n}-c<-\varepsilon\right\} \bigcup\left\{X_{n}-c>\varepsilon\right\}\right] \\
& =P\left[X_{n}>c+\varepsilon\right]+P\left[X_{n}<c-\varepsilon\right] \\
& \leq 1-P\left[X_{n} \leq c+\varepsilon\right]+P\left[X_{n} \leq c-\varepsilon\right] .
\end{aligned}
$$

Bila masing-masing ruas dilimitkan, maka untuk $n \rightarrow \infty$ akan diperoleh

$$
\begin{aligned}
\lim _{n \rightarrow \infty} P\left(\left|X_{n}-c\right|>\varepsilon\right) & \leq \lim _{n \rightarrow \infty}\left(1-P\left[X_{n} \leq c+\varepsilon\right]+P\left[X_{n} \leq c-\varepsilon\right]\right) \\
& =\lim _{n \rightarrow \infty}(1-F(c+\varepsilon)+F(c-\varepsilon)) .
\end{aligned}
$$

Karena $F_{X_{n}}(x)$ konvergen ke $F_{X}(x)$ yang menyebar secara degenerate ke $c$, maka

$$
\lim _{n \rightarrow \infty} P\left(\left|X_{n}-X\right|>\varepsilon\right)=1-1+0=0 .
$$

Dengan kata lain, $\left\{X_{n}\right\}$ konvergen dalam peluang ke $c$.

Proposisi 2.5. [3] Barisan peubah acak $\left\{X_{n}\right\}$ konvergen dalam peluang ke peubah acak $X$ jika dan hanya jika

$$
\lim _{n \rightarrow \infty} E\left[\frac{\left|X_{n}-X\right|}{1+\left|X_{n}-X\right|}\right]=0
$$

Bukti. $(\Rightarrow)$ Barisan peubah acak $\left\{X_{n}\right\}$ konvergen dalam peluang ke peubah acak $X$, maka untuk setiap $\varepsilon>0$ berlaku $\lim _{n \rightarrow \infty} P\left(\left|X_{n}-X\right| \geq \varepsilon\right)=0<\varepsilon$.

Perhatikan bahwa

$$
\begin{aligned}
E\left(\frac{\left|X_{n}-X\right|}{1+\left|X_{n}-X\right|}\right) & =\int_{\left[\left|X_{n}-X\right| \geq \varepsilon\right]} \frac{\left|X_{n}-X\right|}{1+\left|X_{n}-X\right|} d P+\int_{\left[\left|X_{n}-X\right|<\varepsilon\right]} \frac{\left|X_{n}-X\right|}{1+\left|X_{n}-X\right|} d P \\
& \leq \int_{\left[\left|X_{n}-X\right| \geq \varepsilon\right]} d P+\int_{\left[\left|X_{n}-X\right|<\varepsilon\right]} \frac{\varepsilon}{1+\varepsilon} d P \\
& =P\left(\left|X_{n}-X\right| \geq \varepsilon\right)+\frac{\varepsilon}{1+\varepsilon} d P \\
& \leq \varepsilon+\frac{\varepsilon}{1+\varepsilon}(1-\varepsilon)<2 \varepsilon
\end{aligned}
$$

untuk setiap $\varepsilon>0$, maka

$$
\lim _{n \rightarrow \infty} E\left(\frac{\left|X_{n}-X\right|}{1+\left|X_{n}-X\right|}\right)=0
$$

$(\Leftarrow)$ Perhatikan bahwa untuk setiap $\varepsilon>0$ berlaku :

$P\left(\left|X_{n}-X\right| \geq \varepsilon\right) \leq \frac{1+\varepsilon}{\varepsilon} \int_{\left[\left|X_{n}-X\right| \geq \varepsilon\right]} \frac{\left|X_{n}-X\right|}{1+\left|X_{n}-X\right|} d P \leq \frac{1+\varepsilon}{\varepsilon} E\left(\frac{\left|X_{n}-X\right|}{1+\left|X_{n}-X\right|}\right)$. 
Untuk $n \rightarrow \infty$ berlaku

$$
\begin{aligned}
\lim _{n \rightarrow \infty} P\left(\left|X_{n}-X\right| \geq \epsilon\right) & \leq \lim _{n \rightarrow \infty}\left(\frac{1+\varepsilon}{\varepsilon} E\left(\frac{\left|X_{n}-X\right|}{1+\left|X_{n}-X\right|}\right)\right) \\
& =\frac{1+\varepsilon}{\varepsilon} \lim _{n \rightarrow \infty} E\left(\frac{\left|X_{n}-X\right|}{1+\left|X_{n}-X\right|}\right) \\
& =\frac{1+\varepsilon}{\varepsilon} .0 \\
& =0 .
\end{aligned}
$$

Dengan kata lain barisan $\left\{X_{n}\right\}$ konvergen dalam peluang ke peubah acak $X$.

Teorema 2.6. [3] Jika barisan peubah acak $\left\{X_{n}\right\}$ konvergen hampir pasti ke peubah acak $X$ maka $\left\{X_{n}\right\}$ konvergen dalam peluang ke $X$.

Bukti. Berdasarkan Lebesque Dominated Convergence Theorem dapat ditulis bahwa

$$
\lim _{n \rightarrow \infty} E\left(\frac{\left|X_{n}-X\right|}{1+\left|X_{n}-X\right|}\right)=E\left(\lim _{n \rightarrow \infty} \frac{\left|X_{n}-X\right|}{1+\left|X_{n}-X\right|}\right)=0 .
$$

$\left\{X_{n}\right\}$ konvergen hampir pasti ke $X$, hal ini berarti bahwa $X_{n}-X \rightarrow 0$, sehingga

$$
\lim _{n \rightarrow \infty} E\left(\frac{\left|X_{n}-X\right|}{1+\left|X_{n}-X\right|}\right)=0
$$

Berdasarkan Proposisi 2.5 diperoleh $\left\{X_{n}\right\}$ konvergen dalam peluang ke $X$.

Teorema 2.7. [2] Jika barisan peubah acak $\left\{X_{n}\right\}$ konvergen dalam peluang ke peubah acak $X$ maka konvergen dalam sebaran ke $X$.

Bukti. Misalkan $F_{X_{n}}(x)=P\left(X_{n} \leq x\right)$ dan $F_{X}(x)=P(X \leq x)$ masing-masing adalah fungsi sebaran dari $X_{n}$ dan $X$. Akan ditunjukkan bahwa $F_{X_{n}}(x) \rightarrow F_{X}(x)$ untuk setiap $x \epsilon C\left(F_{X}(x)\right)$ dimana $C\left(F_{X}(x)\right)$ adalah himpunan fungsi $F_{X}(x)$ yang kontinu. Perhatikan bahwa untuk setiap $\varepsilon>0$

$$
\begin{aligned}
F_{X_{n}}(x) & =P\left(X_{n} \leq x\right) \\
& =P\left(X_{n} \leq x, X \leq x+\varepsilon\right)+P\left(X_{n} \leq x, X>x+\varepsilon\right) \\
& \leq P(X \leq x+\varepsilon)+P\left(X_{n}-X \leq x-X, x-X<-\varepsilon\right) \\
& =P(X \leq x+\varepsilon)+P\left(X_{n}-X<-\varepsilon\right) \\
& \leq P(X \leq x+\varepsilon)+P\left(X_{n}-X<-\varepsilon\right)+P\left(X_{n}-X>\varepsilon\right) \\
& =P(X \leq x+\varepsilon)+P\left(\left|X_{n}-X\right|>\varepsilon\right) \\
& =F_{X}(x+\varepsilon)+P\left(\left|X_{n}-X\right|>\varepsilon\right.
\end{aligned}
$$

sehingga

$$
F_{X_{n}}(x) \leq F_{X}(x+\varepsilon)+P\left(\left|X_{n}-X\right|>\varepsilon\right) .
$$

Dengan cara yang sama diperoleh

$$
F_{X}(x-\varepsilon) \leq F_{X_{n}}(x)+P\left(\left|X_{n}-X\right|>\varepsilon\right),
$$


sehingga

$$
F_{X}(x-\varepsilon)-P\left(\left|X_{n}-X\right|>\varepsilon\right) \leq F_{X_{n}}(x) \leq F_{X}(x+\varepsilon)+P\left(\left|X_{n}-X\right|>\varepsilon\right) .
$$

Karena $\left\{X_{n}\right\}$ konvergen dalam peluang ke $X$, maka untuk $n \rightarrow \infty$ diperoleh

$$
F_{X}(x-\varepsilon) \leq \lim _{n \rightarrow \infty} P\left(X_{n} \leq X\right) \leq F_{X}(x+\varepsilon) .
$$

Berdasarkan asumsi, fungsi sebaran $F_{X}(x)$ kontinu pada $x$, sehingga jika $\varepsilon \rightarrow 0$ maka $F_{X}(x-\varepsilon) \rightarrow F_{X}(X)$ dan $F_{X}(x+\varepsilon) \rightarrow F_{X}(X)$. Untuk $\varepsilon>0$ maka $\lim _{\varepsilon \rightarrow 0} F_{X}(x-\varepsilon)=F_{X}(x) \operatorname{dan}_{\lim _{\varepsilon \rightarrow 0}} F_{X}(x+\varepsilon)=F_{X}(x)$.

Perhatikan bahwa

$$
\begin{array}{r}
\lim _{\varepsilon \rightarrow 0} F_{X}(x-\varepsilon) \leq \lim _{\varepsilon \rightarrow 0}\left[\lim _{n \rightarrow \infty} P\left(X_{n} \leq x\right)\right] \leq \lim _{\varepsilon \rightarrow 0} F_{X}(x+\varepsilon) \\
\left.F_{X}(x) \leq \lim _{n \rightarrow \infty} P\left(X_{n} \leq x\right)\right] \leq F_{X}(x)
\end{array}
$$

sehingga $\lim _{n \rightarrow \infty} P\left(X_{n} \leq x\right)=P(X \leq x)$. Dengan kata lain, $F_{X_{n}}(x) \rightarrow F_{X}(x)$ untuk $x \epsilon C\left(F_{X}(x)\right)$, artinya $F_{X_{n}}$ konvergen dalam sebaran ke $F_{X}(x)$.

Teorema 2.6 menyatakan bahwa jika barisan peubah acak $\left\{X_{n}\right\}$ konvergen hampir pasti ke peubah acak $X$ maka $\left\{X_{n}\right\}$ konvergen dalam peluang ke $X$ dan Teorema 2.7 menyatakan bahwa jika barisan peubah acak $\left\{X_{n}\right\}$ konvergen dalam peluang ke peubah acak $X$ maka $\left\{X_{n}\right\}$ konvergen dalam sebaran ke $X$. Dari kedua teorema tersebut dapat dinyatakan bahwa jika barisan peubah acak $\left\{X_{n}\right\}$ konvergen hampir pasti ke peubah acak $X$ maka $\left\{X_{n}\right\}$ konvergen dalam sebaran ke $X$.

\section{Ilustrasi Tentang Keterkaitan Antara Konvergen Hampir Pasti, Konvergenan Dalam Peluang, dan Konvergen Dalam Sebaran}

Misalkan $X_{1}, X_{2}, \ldots$ suatu barisan peubah acak yang menyebar secara bebas dan identik menurut sebaran normal dengan $E\left(X_{i}\right)=\mu=0$ dan $\operatorname{Var}\left(X_{i}\right)=\sigma^{2}=1$. Misalkan pula didefinisikan dua peubah acak yang baru yaitu $X=0$ dan $\bar{X}_{n}=$ $\frac{1}{n} \sum_{i=1}^{n} X_{i}$. Maka $\bar{X}_{n}$ merupakan peubah acak normal dengan $E\left(\bar{X}_{n}\right)=0$ dan $\operatorname{Var}\left(\bar{X}_{n}\right)=\frac{1}{n}$. Dapat dilihat bahwa untuk setiap $\varepsilon>0$ berlaku

$$
P\left(\lim _{n \rightarrow \infty}\left|\bar{X}_{n}-X\right|<\varepsilon\right)=P\left(\lim _{n \rightarrow \infty}\left|\bar{X}_{n}-0\right|<\varepsilon\right)=1,
$$

artinya, $\bar{X}_{n}$ konvergen hampir pasti ke peubah acak $X$.

Dengan menggunakan ketaksamaan Chebyshev, selanjutnya akan dibuktikan $\bar{X}_{n}$ konvergen dalam peluang ke peubah acak $X$. Perhatikan bahwa untuk setiap $\varepsilon>0$,

Sehingga diperoleh

$$
\begin{aligned}
P\left(\left|\bar{X}_{n}-X\right| \geq \varepsilon\right) & =P\left(\left|\bar{X}_{n}-0\right| \geq \varepsilon\right) \\
& \leq \frac{\operatorname{Var}\left(\bar{X}_{n}\right)}{\varepsilon^{2}} \\
& =\frac{1}{n \varepsilon^{2}} .
\end{aligned}
$$

$$
\begin{aligned}
& P\left(\left|\bar{X}_{n}-X\right| \geq \varepsilon\right)=P\left(\left|\bar{X}_{n}-0\right| \geq \varepsilon\right) \leq \frac{1}{n \varepsilon^{2}} \\
& \lim _{n \rightarrow \infty} P\left(\left|\bar{X}_{n}-X\right| \geq \varepsilon\right) \leq \lim _{n \rightarrow \infty} \frac{1}{n \varepsilon^{2}}=0 .
\end{aligned}
$$


yang berarti bahwa $\bar{X}_{n}$ konvergen dalam peluang ke peubah acak $X$.

Selanjutnya akan diperlihatkan bahwa $\bar{X}_{n}$ konvergen dalam sebaran ke $X$, karena $X_{i} \sim N(0,1)$ maka $\bar{X}_{n}$ menyebar menurut sebaran normal dengan $E\left(\bar{X}_{n}\right)=$ 0 dan $\operatorname{Var}\left(\bar{X}_{n}\right)=\frac{1}{n}$ sehingga fungsi kepekatan peluang dari $\bar{X}_{n}$ adalah

$$
\begin{aligned}
f(x) & =\frac{1}{\sqrt{2 \pi} \sqrt{\frac{1}{n}}} e^{-\frac{1}{2}(x-0)^{2} n} \\
& =\frac{1}{\sqrt{\frac{1}{n}} \sqrt{2 \pi}} e^{-\frac{n x^{2}}{2}}, \text { untuk }-\infty<x<\infty
\end{aligned}
$$

dan fungsi sebaran kumulatifnya adalah

$$
\begin{aligned}
F_{\bar{X}_{n}}(x) & =\int_{-\infty}^{x} f(x) d x \\
& =\int_{-\infty}^{x} \frac{1}{\sqrt{\frac{1}{n}} \sqrt{2 \pi}} e^{\frac{-n w^{2}}{2}} d w
\end{aligned}
$$

Selanjutnya misalkan $v=\sqrt{n} w$ sehingga $d v=\sqrt{n} d w$. Jika $w \rightarrow-\infty$ maka $v \rightarrow-\infty$. Jika $w=x$ maka $v=\sqrt{n} x$. Sehingga fungsi sebaran kumulatif dari $\bar{X}_{n}$ dapat dituliskan kembali sebagai berikut.

$$
\begin{aligned}
F_{\bar{X}_{n}}(x) & =\int_{-\infty}^{\sqrt{n} x} \frac{1}{\sqrt{\frac{1}{n}}} \frac{1}{\sqrt{2 \pi}} e^{-\frac{v^{2}}{2}} \frac{1}{\sqrt{n}} d w \\
& =\int_{-\infty}^{\sqrt{n} x} \frac{1}{\sqrt{2 \pi}} e^{-\frac{v^{2}}{2}} .
\end{aligned}
$$

Oleh karena itu sebaran pelimitan dari $F_{\bar{X}_{n}}(x)$ adalah

$$
\lim _{n \rightarrow \infty} F_{\bar{X}_{n}}(x)=\lim _{n \rightarrow \infty} \int_{-\infty}^{\sqrt{n} x} \frac{1}{\sqrt{2 \pi}} e^{-\frac{v^{2}}{2}} d v
$$

Selanjutnya akan dicari nilai limit dari sebaran pelimitan diatas, yaitu

$$
\begin{array}{r}
\lim _{n \rightarrow \infty} F_{\bar{X}_{n}}(x<0)=\lim _{n \rightarrow \infty} \int_{-\infty}^{-\infty} \frac{1}{\sqrt{2 \pi}} e^{-\frac{v^{2}}{2} d v}=0, \text { untuk } x<0 \\
\lim _{n \rightarrow \infty} F_{\bar{X}_{n}}(0)=\lim _{n \rightarrow \infty} \int_{-\infty}^{0} \frac{1}{\sqrt{2 \pi}} e^{-\frac{v^{2}}{2} d v}=\frac{1}{2}, \text { untuk } x=0 \\
\lim _{n \rightarrow \infty} F_{\bar{X}_{n}}(x>0)=\lim _{n \rightarrow \infty} \int_{-\infty}^{\infty} \frac{1}{\sqrt{2 \pi}} e^{-\frac{v^{2}}{2} d v}=1, \text { untuk } x>0
\end{array}
$$

Terlihat bahwa saat $x=0$ merupakan nilai tengah dari sebaran dengan peluang terjadi 1. Maka diperoleh

$$
\lim _{n \rightarrow \infty} F_{\bar{X}_{n}}(x)=F_{X}(x)
$$

untuk setiap titik kontinu di $F_{X}(x)$, di mana peubah acak $X$ selalu bernilai tunggal yaitu pada $x=0$ dengan sebaran

$$
F_{X}(x)=\left\{\begin{array}{l}
0, x<0 \\
1, x \geq 0
\end{array}\right.
$$

yang merupakan suatu fungsi sebaran degenerate. 
16 Vira Agusta dkk.

\section{Kesimpulan}

Misalkan $\left\{X_{n}\right\}$ barisan peubah acak yang didefinisikan pada suatu ruang peluang $(\Omega, \mathfrak{F}, P)$. Jika barisan peubah acak $\left\{X_{n}\right\}$ konvergen hampir pasti ke suatu peubah acak $X$ maka $\left\{X_{n}\right\}$ konvergen dalam peluang ke $X$. Jika barisan peubah acak $\left\{X_{n}\right\}$ konvergen dalam peluang ke peubah acak $X$ maka $\left\{X_{n}\right\}$ konvergen dalam sebaran ke $X$. Dengan demikian, jika barisan peubah acak $\left\{X_{n}\right\}$ konvergen hampir pasti ke peubah $X$ maka $\left\{X_{n}\right\}$ konvergen dalam sebaran ke $X$.

\section{Ucapan Terima kasih}

Penulis mengucapkan terima kasih kepada Ibu Maiyastri, Ibu Izzati Rahmi, dan Ibu Riri Lestari yang telah memberikan masukan dan saran sehingga paper ini dapat diselesaikan dengan baik.

\section{Daftar Pustaka}

[1] Casella, G. dan R. L. Berger. 1990. Statistical Inference. Ed. Ke-1 Wadsworth \& Brooks/Cole, Pasific Grove, California.

[2] Grimmett, G. R. dan D.R. Stirzaker. 1992. Probability and Random Processes. Ed. Ke-2. Clarendon Press. Oxford.

[3] Li, Zenghu. 2005. Probability Theory. School of Mathematical Sciences Beijing Normal University, China. 